\title{
INHIBITION OF CHOLESTEROL SIDE-CHAIN CLEAVAGE BY 22-AZACHOLESTEROL*
}

\author{
Souheir E. El Masry, $†$ James A. Fee, Ahmed H. El Masry $\dagger$ and Raymond E. Counsell \\ College of Pharmacy (S.F.F.M., A.H.F.M. and R.F.C.), and Biophysics Research \\ Division (J.A.F.). Institute of Science and Technology. University of Michigan, \\ Ann Arbor. MI 48109, U.S.A.
}

(Received 29 June 1976; accepted 27 September 1976)

\begin{abstract}
The side-chain of cholesterol is oxidatively cleaved by a cytochrome P-450-dependent enzyme system present in mammalian adrenal mitochondria. The reaction was postulated to proceed via one or more hydroxylated intermediates. Inhibition of the reaction by the potent inhibitor 22-azacholesterol did not result in a build-up of the postulated intermediates: (20S)-20-hydroxycholesterol, (22R)-22-hydroxycholesterol, (20R,22R)-20,22-dihydroxycholesterol or (20S)-cholesterol hydroperoxide. Spectral studies indicate a modified type II spectrum for the reaction of 22-azacholesterol with adrenal mitochondrial cytochrome P-450. In addition, spectral and electron spin resonance studies indicate a common interaction of cholesterol and 22-azacholesterol with the cytochrome. Although this study does not resolve the question of the intermediacy of the oxygenated derivatives in the cleavage reaction, it indicates that the binding of 22-azacholesterol depends on its steroid structure rather than on its amine character. $A$ discussion of the proximity of the heme to the substrate binding site is also presented.
\end{abstract}

It is well established that the metabolism of cholesterol by mammalian adrenal mitochondria proceeds by an oxidative cleavage of the side-chain resulting in the formation of pregnenolone and a 6-carbon fragment, isocaproic aldehyde $[1,2]$. The reaction requires NADPH and is catalyzed by cytochrome P-450 [3]. It has been hypothesized that the cleavage of the $\mathrm{C}_{20}-\mathrm{C}_{22}$ bond of cholesterol proceeds via the formation of a monohydroxy-, followed by a dihydroxy-intermediate. This is supported by the observations that (a) (20S)-20-hydroxycholesterol (Fig. 1) had been isolated in minute amounts from bovine adrenal preparations [4] and separated during the metabolism of $\left[{ }^{14} \mathrm{C}\right]$ cholesterol in vitro [5], and (b) (20S)-20hydroxy- and (20R,22R)-20,22-dihydroxycholesterol (Fig. 1) were more efficiently transformed to pregnenolone than cholesterol $[6,7]$. More recently, however, analysis of kinetic data [8-10] has indicated that (20R,22R)-20,22-dihydroxycholesterol arises directly from cholesterol without the intermediacy of (20S)20-hydroxy- or (22R)-22-hydroxycholesterol (Fig. 1). Such a transformation could occur by the intermediacy of a (20S)-hydroperoxide (Fig. 1) as suggested by van Lier et al. [11-13] or by concerted enzymatic hydroxylations in which the mono-hydroxylated intermediates and transient free radicals or ionic species are not released in the medium [14].

In our previous work, 22-azacholesterol (Fig. 1) was reported to be a potent competitive inhibitor of the cholesterol side-chain cleavage (CSSC) reaction [15]. We have used this inhibitor as a tool to provide more information on the CSSC reaction. In this paper, we report the effects of this agent on the formation of the hydroxylated intermediates and on the optical

*This work was supported by U.S. Public Health Scrvice Grant HE-11274, and also GM-21519 (J. A. F.).

+ Present address: Abbott Laboratories. North Chicago. IL 60064 and magnetic properties of adrenal mitochondrial cytochrome P-450.

\section{MATERIALS AND METHODS}

Materials. NADP, glucose 6-phosphate and glucose 6-phosphate dehydrogenase were purchased from Sigma Chemical Co., St. Louis, MO; $\left[26-{ }^{14} \mathrm{C}\right]$ cholesterol (sp. act. $58 \mathrm{mCi} / \mathrm{m}$-mole) and $\left[7-{ }^{3} \mathrm{H}\right\rceil$ cholesterol, $10 \mathrm{Ci} / \mathrm{m}$-mole, were obtained from New England Nuclear. A PCS scintillation mixture was obtained from Amersham/Searle Co. A sample of 22-azacholesterol was kindly supplied by Searle Laboratories, Chicago, IL. Silica gel plates, $0.25-\mathrm{mm}$ thick, were obtained from E. Merck GmbH Darmstadt. Samples of (20S)-20-hydrox ycholesterol, (22R)-22-hydroxycholesterol and (20R,22R)-dihydroxycholesterol were kindly supplied by Dr. Marcel Gut, Worcester Foundation for Experimental Biology, Shrewsbury, MA, and later synthesized in our laboratory by Dr. J. Bristol (presently at Schering Co., NJ). A sample of cholesterol hydroperoxide was kindly supplied by Dr. Johan van Lier at the Centre Hospitalier Univercitaire, Sherbrooke, Quebec, Canada.

Enzyme preparations. An acetone-dried powder was prepared from beef adrenal cortical mitochondria as described previously [15]. Male Sprague-Dawley rats weighing $100-150 \mathrm{~g}$ were used for the preparation of liver microsomes. The animals were killed by a blow on the head and decapitated; their livers were perfused in situ with a cold $1.15 \% \mathrm{KCl}$ solution, excised and homogenized in 4 vol. of isotonic $\mathrm{KCl}$ solution. The homogenate was then differentially centrifuged for $20 \mathrm{~min}$ at $9,000 \mathrm{~g}$ and for $60 \mathrm{~min}$ at $105,000 \mathrm{~g}$. The resultant microsomal pellet was suspended in $4 \mathrm{vol}$, of $\mathrm{KCl}$ solution. Protein concentrations were measured by the method of Lowry et al. [16].

Separation of the "possible" intermediates of the CSSC reaction. Incubations were carried out using 
<smiles>CC(C)CCC(O)C(C)C1CCC2C3CC=C4CC(O)CCC4(C)C3CCC12C</smiles>

(b)<smiles>CC(C)CCCC(C)(O)C1CCC2C3CC=C4CC(O)CCC4(C)C3CCC21C</smiles>

(c)

(d)<smiles>CC(C)CCNC(C)C1CCC2C3CCC4CC(O)CCC4(C)C3CCC12C</smiles>

(e)

Fig. 1. Structural formulae of 22-azacholesterol and the different oxygenated derivatives of cholesterol implicated in its metabolism: (a) (20S)-20-hydroxycholesterol; (b) (22R)-22-hydroxycholesterol; (c)

(20,22R)-20,22-dihydroxycholesterol; (d) (20S)-20-hydroperoxycholesterol; and (e) 22-azacholesterol.

$3.5 \mathrm{mg}$ of acetone powder protein in $0.02 \mathrm{M}$ phosphate buffer, $\mathrm{pH}$ 7.4. This was supplemented with an NADPH-generating system consisting of $0.1 \mu$ mole NADP, $5 \mu$ moles glucose 6-phosphate and 1 unit of glucose 6-phosphate dehydrogenase in a total volume of $0.75 \mathrm{ml}$. The mixture was preincubated for $5 \mathrm{~min}$ at $37^{\circ}$; then approximately $1 \mu \mathrm{Ci}$ of $\left[26-{ }^{14} \mathrm{C}\right]$ cholesterol $[7-8 \mu \mathrm{g}$ freshly purified by thin-layer chromatography (t.l.c.) using a system of benzene-ethyl acetate, 3:2] was added and the incubation continued at 37 for $20 \mathrm{~min}$ under subdued light. A blank reaction mixture, devoid of an NADPH-generating system was subjected to the same incubation. At the end of the incubation period. the reaction mixture was saturated with anhydrous sodium sulfate, $100 \mu \mathrm{g}$ each of (20S)-20-hydroxy- (22R)-22-hydroxy- and (20R.22R)-20,22-dihydroxycholesterol in addition to $5 \mu \mathrm{C} i(\simeq 100 \mu \mathrm{g})$ of $\left[7-{ }^{3} \mathrm{H}\right]$ cholesterol were added and the mixture was extracted three times with $4 \mathrm{ml}$ of methylene chloride. The combined extracts were filtered through glass wool, concentrated under reduced pressure (not evaporating them to dryness), and then applied as a fine streak on Silica gel plates, $0.25 \mathrm{~mm}$ thick. The chromatoplates were irrigated five times in an atmosphere of nitrogen using a system of hexane ether-glacial acetic acid (140:8:18). All operations were carried out in the dark or in subdued light. The plates were exposed to iodine to visualize the steroids. They were next scanned for ${ }^{14} \mathrm{C}$-labeled compounds using a t.l.c. scanner, and when the iodine was bleached, the Silica was scraped off the plates and counted in a PCS mixture.
Difference spectroscopy. Difference spectra were recorded using an Aminco Chance spectro-photometer operating in the dual beam dual wavelength model. Equal volumes of the enzyme preparation were used in the sample and reference cuvettes of $1.0 \mathrm{~cm}$ path length. Cytochrome $\mathrm{P}-450$ in hepatic microsomal or adrenal mitochondrial preparations were carried out as described by Omura and Sato [17]. The amount of cytochrome P-450 was estimated by assuming a molecular absorptivity difference of $91 \mathrm{mM}^{-1} \mathrm{~cm}^{-1}$ between 450 and $490 \mathrm{~nm}$ bands in the CO-treated difference spectrum [17].

Binding of cholesterol and 22-azacholesterol was measured as the sum of the absorbance changes of the peak and trough of the spectral changes caused by the addition of cholesterol or 22-azacholesterol. The cuvettes contained, in a final volume of $3 \mathrm{ml}$, a liver microsomal preparation or mitochondrial acetone powder in a $0.02 \mathrm{M}$ phosphate buffer, $\mathrm{pH} 7.4$. as shown in the legends of the figures. Cholesterol and 22-azacholesterol were dissolved in ethylene glycol. An equivalent volume of the solvent was added to the reference sample cuvette.

Electron Paramagnetic Resonance (EPR) measurement. EPR spectroscopy was performed with a Varian V-4502 spectrometer equipped with a helium or nitrogen sample cooling system. The procedures followed were generally as described by Palmer [18].

\section{RESLLTS}

Changes in the rates of formation of (20S)-20-hydroxy, (22R)-22-hydroxy- and (20R,22R)-20,22-dihy- 


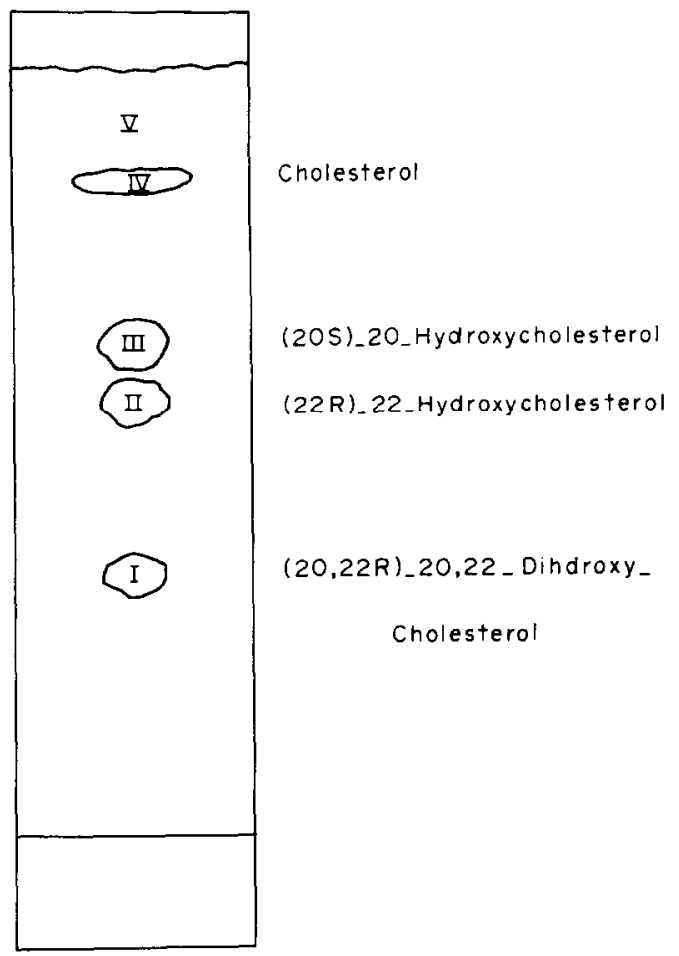

Fig. 2. Separation of cholesterol and the different hydroxylated derivatives on thin-layer chromatographic plates. For details, refer to text.

droxycholesterol after inhibition by 22-azacholesterol. Cholesterol labeled with ${ }^{14} \mathrm{C}$ in the 26 position was chosen as a substrate of the reaction, since metabolic cleavage of the side-chain will result in loss of the label from products such as pregnenolone and progesterone. Thus, attention could be focused on the separation of the suggested hydroxylated intermediates having an intact side-chain.

Although great care was taken to minimize air oxidation and decomposition of cholesterol, it is well established that cholesterol is quite labile and its decomposition products are similar to the oxygenated products formed during enzymatic metabolism $[19,20]$. On the other hand, when these different oxygenated derivatives were detected during the metabolism of cholesterol, they did not amount to more than 1 per cent of the total cholesterol present [8]. Moreover. several investigators have even failed to detect appreciable amounts of these oxygenated derivatives using either an adrenal acetone powder [21] or a purificd cytochrome P-450 preparation [22]. Nonetheless, the following assay conditions were developed to differentiate enzymatically derived products from non-enzymatic artifacts. Blank experiments differed from control experiments only in the absence of an NADPH-generating system and were, therefore. subject to the non-enzymatic decomposition occurring during the $20 \mathrm{~min}$ of incubation at $37^{\circ}$. Figure 2 shows the separation of cholesterol and its hydroxylated derivatives by t.l.c. In the control experiment, a large ${ }^{14} \mathrm{C}$-labeled peak was observed to run ahead of cholesterol on the radiochromatogram (area V). Its activity was usually proportional to that expected for the cleaved side-chain. When the methylene chloride extracts were either evaporated to dryness, washed, or oxidized. the peak in area $V$ from the chromatogram was decreased or completely removed. These results are consistent with the reports of Burstein et al. [23] and, more recently, of Kraaipoel et al. [24] who noted that. in a 20-min incubation, isocaproic aldehyde is the major cleavage product and isocaproic acid is only obtained after incubation for $2 \mathrm{hr}$ or longer.

The areas corresponding to (20S)-20-hydroxycholesterol (zone III), (22R)-22-hydroxycholesterol (zone II) and (20R,22R)-20.22-dihydroxycholesterol (zone I) plus the areas corresponding to cholesterol (zone IV) and isocaproic aldehyde (zone $V$ ) were scraped from the plates and counted. The remaining areas on the plates were also counted except the origin. The latter retained iodine and the counts were unreliable due to quenching. In the few cases where quenching was controlled. the total ${ }^{14} \mathrm{C}$-radioactivity at the origin varied between 1400 and 2000 dis.min. This minimal amount of radioactivity is believed to be the small amount of isocaproic acid formed which, if present, would be expected to remain at the origin.

The partition of radioactivity in the different zones is presented in Table 1. Examination of this table shows that even freshly purified cholesterol develops some decomposition products during extraction and chromatographic work-up. These products, however, correspond to less than 1 per cent of the cholesterol present. The second column of each section of Table 1 depicts the ratio of ${ }^{3} \mathrm{H}$ dis. $/ \mathrm{min} /{ }^{14} \mathrm{C}$ dis. $/ \mathrm{min}$ in the different zones of the plate. This ratio is either an indication of a differential lability of $\left[7-{ }^{3} \mathrm{H}\right]$ choles-

Table 1. Partition of radioactivity in the different areas of the chromatogram

\begin{tabular}{|c|c|c|c|c|c|c|c|c|c|}
\hline \multirow[b]{2}{*}{$\begin{array}{l}\text { Areas of the } \\
\text { chromatogram }\end{array}$} & \multicolumn{3}{|c|}{ Blank } & \multicolumn{3}{|c|}{ Control } & \multicolumn{3}{|c|}{ Inhibited } \\
\hline & $\begin{array}{c}{ }^{14} \mathrm{C} \\
\text { (dis./min) }\end{array}$ & ${ }^{3} \mathrm{H} /{ }^{14} \mathrm{C}$ & $\begin{array}{l}\text { Per cent of } \\
\text { recovered } \\
{ }^{14} \mathrm{C}^{*}\end{array}$ & 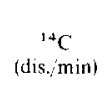 & ${ }^{3} \mathrm{H}:{ }^{1+} \mathrm{C}$ & $\begin{array}{l}\text { Per cent of } \\
\text { recovered } \\
{ }^{14} \mathrm{C}^{*}\end{array}$ & ${ }^{1+C}$ & ${ }^{3} \mathrm{H}^{14} \mathrm{C}$ & $\begin{array}{l}\text { Per cenl of } \\
\text { recovered } \\
{ }^{14} \mathrm{C}^{*}\end{array}$ \\
\hline 1 & & & & & & & & & \\
\hline $\begin{array}{l}\text { (20.22R-di-OH- } \\
\text { cholesterol) } \\
\text { Il }\end{array}$ & 1.464 & 4.94 & 0.026 & 7.874 & 1.30 & 0.326 & 5.376 & 1.34 & 0.184 \\
\hline $\begin{array}{l}\text { (22R } \mathrm{OH} \text {-cholesterol) } \\
\text { III }\end{array}$ & 2,017 & 39.00 & 0.036 & 6.340 & $13.6 \mathrm{]}$ & 0.262 & 6,000 & 11.87 & 0.205 \\
\hline $\begin{array}{l}\text { (20S-OH-cholesterol) } \\
\text { IV }\end{array}$ & 3,084 & 16.98 & 0.055 & 11.914 & 5.47 & 0.494 & 7.492 & 4.78 & 0.256 \\
\hline $\begin{array}{l}\text { (Cholesterol) } \\
\mathrm{V}\end{array}$ & $5.5 \times 10^{6}$ & 2.48 & 99.42 & $1.21 \times 10^{6}$ & 11.18 & 50.33 & $2.36 \times 10^{h}$ & 5.71 & 80.98 \\
\hline $\begin{array}{l}\text { (lsocaproic aldehyde } \\
\text { area) }\end{array}$ & 3.553 & 2.98 & 0.063 & $1.03 \times 10^{6}$ & 0.065 & 42.92 & $0.45 \times 10^{t}$ & 0.507 & 15.29 \\
\hline
\end{tabular}

* Percentage of the total ${ }^{14} \mathrm{C}$ recovered from the plates. 
terol vs $\left[26-{ }^{14} \mathrm{C}\right]$ cholesterol, or, most probably, an indication of the presence of endogenous contaminants in the tritiated cholesterol which could not be removed by the single chromatographic purification step. In the blank experiment, the few hundred dis./ min present in the isocaproic aldehyde zone were most probably due to contamination by cholesterol (which immediately follows), since they exhibit the same ${ }^{3} \mathrm{H} /{ }^{14} \mathrm{C}$ ratio as cholesterol. The radioactivity in the different zones is not, to a major extent. the result of a trailing of cholesterol on the plate on the basis that multiple chromatographic runs effected fairly good separation of cholesterol, as evidenced by the presence of different delineated zones having different zonal ratios of ${ }^{3} \mathrm{H}$ and ${ }^{14} \mathrm{C}$ dis./min.

The recovery of $\left[26-{ }^{14} \mathrm{C}\right]$ cholesterol using $\left[7-{ }^{3} \mathrm{H}\right]$ cholesterol as internal standard varied between 60 and 70 per cent. In the control experiments, there was a concomitant build-up of radioactivity in the areas corresponding to the mono- and dihydroxy-derivatives of cholesterol and, of course, isocaproic aldehyde. However, in some experiments, the build-up of radioactivity in the isocaproic aldehyde area was less than theoretical. This may have been due to volatilization of the aldehyde during concentration of the methylene chloride extracts. In the calculations presented in Table 1, use is made of the presence of decomposition products of the triated cholesterol. Assuming that similar decomposition products will be present in the blank, control and experimental preparations, the ratio of ${ }^{3} \mathrm{H} /{ }^{14} \mathrm{C}$ rather than ${ }^{14} \mathrm{C}$ dis./ min will then be a more accurate measure of changes in total ${ }^{14} \mathrm{C}$ dis./min.

In the controls shown in Table $1,0.30$ per cent of the added cholesterol was recovered as (20R,22R)-20,22-dihydroxycholesterol and 0.26 per cent as (22R)-22-hydroxycholesterol. This agrees with the report of Burstein and Gut [8] who, using slightly different conditions, obtained 0.8 per cent of the added cholesterol as the dihydroxy derivative and 0.6 per cent as the $22 \mathrm{R}$-hydroxy derivative. The highest relative counts $(0.44$ per cent) were detected in the 20 -hydroxycholesterol area. This is in contrast to Burstein et al. [9] who could not recover more than 0.1 per cent of the added cholesterol as the 20-hydroxylated derivative. Another labeled material running ahead of the (20S)-20-hydroxycholesterol area (not shown in Table 1) was also detected. Van Lier and Smith [25] have postulated the formation of $20 \alpha$-hydroperoxide in the cleavage of the side-chain of cholesterol. However, they could not unequivocally conclude that it was not due solely to autoxidation [20]. A sample of $20 \alpha$-hydroperoxide, kindly supplied by Dr. van Lier, was found to migrate slower than $20 \alpha$-hydroxycholesterol and may be responsible for some of the activity present in the $20 \alpha$-hydroxycholesterol area.

Inhibition of the reaction by 22 -azacholesterol (Table 1) resulted in the expected decrease in the metabolism of $\left[{ }^{14} \mathrm{C}\right]$ cholesterol and formation of $\left[{ }^{14} \mathrm{C}\right]$ isocaproic aldehyde. Most importantly, however, is the finding that 22-azacholesterol caused no accumulation of any of the hydroxylated intermediates implicated in the CSSC reaction. Thus, 22-azacholesterol must exert its inhibitory action at a very early stage in the reaction.
Since these observations could have resulted from an interaction of 22-azacholesterol with cytochrome P-450, the terminal oxidase involved in the cleavage reaction, it was of interest to conduct a spectral analysis of this interaction.

Spectral binding of cholesterol and 22-azacholesterol to adrenal mitochondrial cytochrome $P-450$. Since the early work of Narasimhulu [26], the literature is replete with spectral studies of the interaction of substrates with various cytochrome P-450-containing preparations. The resulting spectra were classified as type I if they presented a peak around $390 \mathrm{~nm}$ and a trough around $420 \mathrm{~nm}$, and as type 11 if they presented a peak at 420 and a trough at $390 \mathrm{~nm}$. Schenkman et al. [27] proposed that the type I and type II difference spectra spectra are caused by the association of the substrates to different sites of the enzyme complex. The type I spectral change is thought to be due to an increase in the polarity of the sixth heme ligand facilitating electron flow to cytochrome P-450. altering heme absorption $[28,29]$ and causing a transition of the heme iron from a low-spin to a high-spin state [30]. The type II spectral change is thought to reflect the coordination at the sixth ligand between the compound and the hemochrome site and a transition of the heme iron from a high- to a low-spin state. A third spectral change, the modified type II, is very similar to a simple type II, and is thought to result from a reversal of the binding to cytochrome P-450 of endogenous type I substrate [31].

As shown in Fig. 3, curve a, cholesterol reacted with bovine adrenal mitochondrial preparation to give a weak type I spectrum with a peak at $390 \mathrm{~nm}$ and a trough at $427 \mathrm{~nm}$. Other workers have obtained either a weak type I spectrum [32] or no spectral alteration [33] with cholesterol. This weak binding of cholesterol may be due to the occupation of its binding sites by endogenous sterols as shown by Chen and Harding [34]. These authors have exhaustively extracted mitochondrial preparations with acetone and ether bringing down the ratio of endogenous cholesterol to cytochrome P-450 from 30 to $0.3-0.5$. Addition of a cholesterol-lecithin emulsion to this

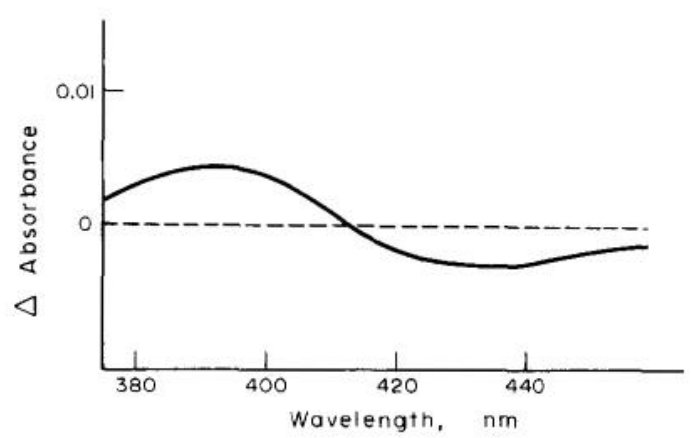

Fig. 3. Binding of cholesterol to adrenal mitochondrial cytochrome P-450. The enzyme preparation was diluted to $17 \mathrm{mg}$ of acetone-dried powder $/ \mathrm{ml}$ with $0.1 \mathrm{M}$ potassium phosphate buffer, $\mathrm{pH}$ 7.4 The solid line (curve a) represents the spectrum obtained upon the addition of $80 \mu \mathrm{M}$ cholesterol in ethylene glycol to the sample cuvette and ethylene glycol to the reference cuvette. The dotted line (curve b) represents the spectrum obtained upon the addition of cholesterol to the sample cuvette in the presence of $40 \mu \mathrm{M}$ 22-azacholesterol in both sample and reference cuvettes. 


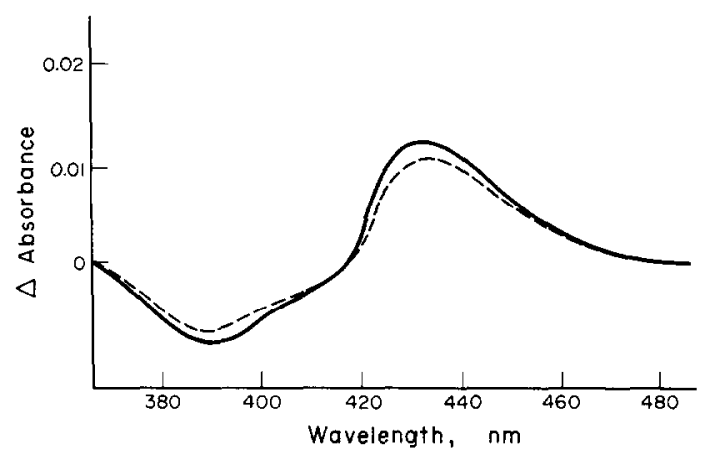

Fig. 4. Binding of 22-azacholesterol to adrenal mitochondrial cytochrome P-450. The enzyme preparation was diluted to $17 \mathrm{mg}$ of acetone-dried powder $/ \mathrm{ml}$ with $0.1 \mathrm{M}$ potassium phosphate buffer, pH 7.4 The solid line (curve a) represents the spectrum obtained upon the addition of $50 \mu \mathrm{M} 22$-azacholesterol in ethylene glycol to the sample cuvette and ethylene glycol to the reference cuvette. The dotted line (curve b) represents the spectrum obtained upon the addition of 22-azacholesterol to the sample cuvette in the presence of $80 \mu \mathrm{M}$ cholesterol in both sample and reference cuvettes.

preparation provided a well-defined type I spectrum ( $\hat{\lambda}_{\max } 387 \mathrm{~nm}$ and $\hat{\lambda}_{\min } 420 \mathrm{~nm}$ ). They also obtained well-defined type I spectra with the hydroxylated derivatives of cholesterol. Earlier, Burstein et al. [35] were unable to detect a consistent correlation between the enzymatic activity of an adrenal mitochondrial preparation and spectral binding with cholesterol. While this casts doubt on the use of spectral binding data, the findings of Chen and Harding [34] offer an explanation for the previous lack of correlation with enzymatic activity.

Figure 4, curve a, shows a "type II" spectrum of 22-azacholesterol ( $\lambda_{\max } 427 \mathrm{~nm}$ and $\lambda_{\min } 388 \mathrm{~nm}$ ) with adrenal mitochondrial preparations. When a saturating concentration of 22-azacholesterol was added to the sample and reference cuvettes, no difference spectrum was observed on subsequent addition of cholesterol to the sample cuvette (Fig. 3, curve b). However, a saturating concentration of cholesterol in both cuvettes only slightly altered the binding spectrum of 22-azacholesterol (Fig. 4, curve b).

A true type II binding, resulting in a low-spin form of cytochrome P-450, is thought to be due to binding at the sixth ligand. Oxygen, carbon monoxide, amines and other nitrogenous compounds ostensively interact in this manner. Several criteria are used to confirm this interaction among which is the ability to displace carbon monoxide from its binding site. Although an amine, 22-azacholesterol does not bring out the hemoprotein nature of cytochrome P-450 in contrast with metyropone, a known type II compound. Thus, in our hands, addition of 22-azacholesterol to the dithionite reduced preparations showed essentially no difference spectrum between the wavelengths 500 and $650 \mathrm{~nm}$ (not shown). This is unlike metyropone which gave single distinct alpha and beta bands at 540 and $566 \mathrm{~nm}$ when the source of the cytochrome was Pseudomonas putida and split peaks when the source was rat liver microsomes [36].

Thus, we may conclude that 22-azacholesterol, although an amine, most probably does not bind with the heme at the oxygen or carbon monoxide binding site but appears to compete with cholesterol at the substrate site. In reality then, the "type II" spectrum is a modified type II and is the result of the displacement of endogenous cholesterol. Similar to cholesterol, 22-azacholesterol can be classified as a type I substrate. In fact, when added to rat liver microsomes, 22-azacholesterol produced a modified type I spectrum (Fig. 5) with a peak at $408 \mathrm{~nm}$ and a trough at $425 \mathrm{~nm}$. Further insight on the interaction of 22-azacholesterol with cytochrome P.450 was obtained by the following EPR study.

EPR measurements of the interaction of cholesterol and 22-azacholesterol with adrenal acetone powder preparation. Cytochrome P-450 exists in either a highspin or a low-spin state; these states are not energetically very far apart and a variety of factors can cause transition from one spin state to another. The highspin ferric ion associated with cylochrome P-450 has been shown to exhibit resonance near a magnetic field corresponding to $g \sim 8$, observable only at very low temperatures $(<20 \mathrm{~K})$, while the low-spin ferric ion yields a rhombic EPR signal centered around $g-2$ and is readily detected at temperatures near liquid nitrogen.

The type I spectral change has been demonstrated to reflect a low-spin ( $S=1 / 2)$ to high-spin ( $S=5 / 2$ ) shift of the ferric ion in $\mathrm{P}-450$ and the modified type II spectral change to reflect a high- to low-spin shift [37].

Since the above described enzymic and optical measurements seem to indicate a common interaction of cholesterol and 22-azacholesterol with adrenal mitochondrial cytochrome $\mathrm{P}-450$, it was of interest to determine the effect of 22-azacholesterol on the high- to low-spin transition of the ferric ion in the cytochrome. Such an experiment would provide further evidence relating to the nature of the type II spectrum. The results of this experiment are presented in Fig. 6.

Examination of the influence of the transition solvent ethylene glycol has indicated that this polyol effects a substantial decrease ( 37 per cent) in the $g \sim 8$ signal (spectra a and $a^{\prime}$ of Fig. 6a), indicating a highto low-spin transition. The same concentration of ethylene glycol plus $150 \mu \mathrm{M} 22$-azacholesterol effected approximately a 70 per cent attenuation of the $g-8$ signal (spectrum b, Fig. 6a). Addition of larger amounts of the solvent and inhibitor did not further

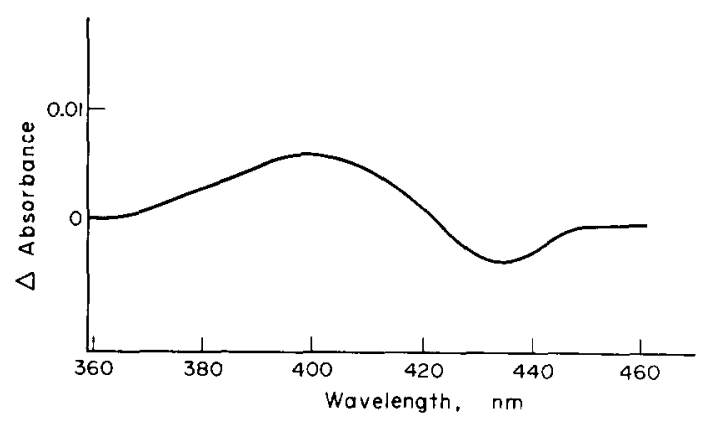

Fig. 5. Binding of 22-azacholesterol to rat liver microsomes. A microsomal preparation containing $1 \mu \mathrm{M}$ cytochrome P-450 was treated with $20 \mu \mathrm{M}$ 22-azacholesterol in ethylene glycol in the sample cuvette and ethylene glycol in the reference cuvette. 


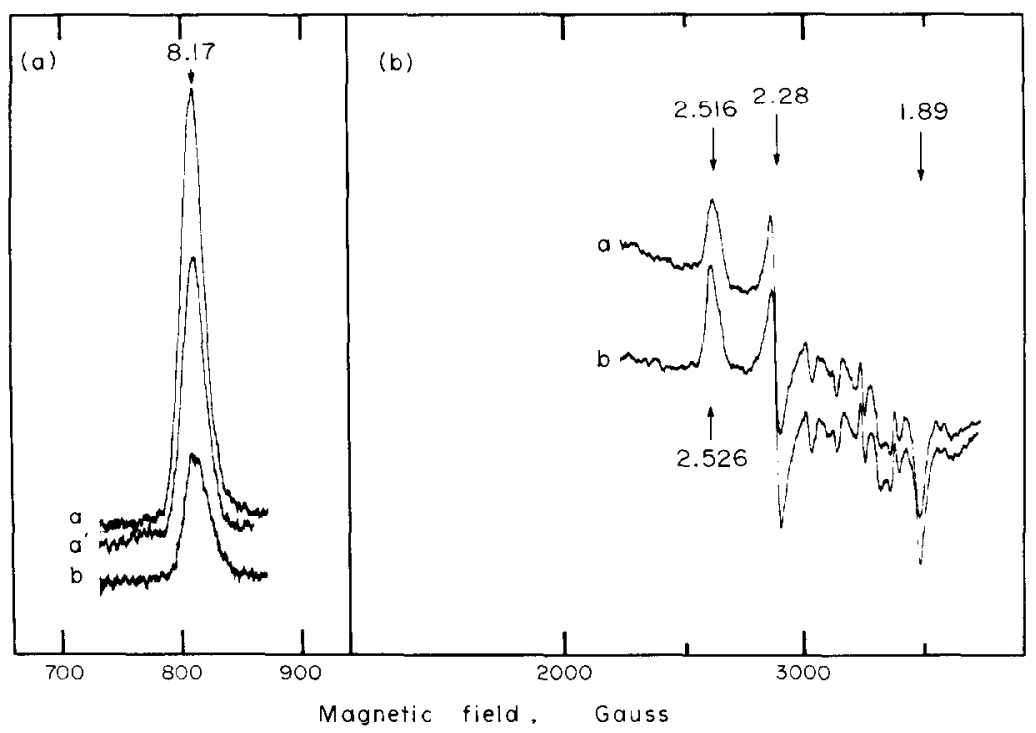

Fig. 6. EPR spectra of adrenal mitochondrial P-450 $(-60 \mu \mathrm{M})$ in the absence and presence of 22-azacholesterol. Panel a: spectra of the low field region. Panel b: spectra of the high field region. Sample preparations: (a) no additions; (a') $40 \mu \mathrm{l}$ ethylenc glycol to $0.5 \mathrm{ml}$ of cnzymc preparation: and (b) 80 nmoles of 22 -azacholesterol in $40 \mu$ ethylene glycol. Recording conditions: (a) temperature. $7.5 \mathrm{~K}$; sweep rate, 100 gauss $/ \mathrm{min}$; microwave power, $30 \mathrm{~mW}$; microwave frequency $9.26 \mathrm{GHz}$; and (b) temperature, $100 \mathrm{~K}$, sweep rate, 200 gauss $/ \mathrm{min}$; microwave power, $5 \mathrm{~mW}$; microwave frequency $9.228 \mathrm{GHz}$. (Common) Modulation amplitude, 9 gauss; modulation frequency, $100(\mathrm{k}) \mathrm{Hz}$; time constant. 1 sec.

lower the $g \sim 8$ signal. The intensity of the $g \sim 6$ signal present in these samples was recorded directly after the $g \sim 8$ signal at reduced spectrometer gain and was found to be constant ( \pm 2 per cent) for all the spectra shown in Fig. 6 . This result insured that the intensity changes in the $g \sim 8$ signal were not caused by spurious temperature differences between different recordings.

FPR spectra were recorded from the same samples as shown in Fig. 6 at nitrogen temperatures. A distinct increase in the low-spin signal on addition of the inhibitor in ethylene glycol was observed as compared to ethylene glycol alone. In separate experiments (not shown), it was demonstrated that ethylene glycol alone increased the overall intensity of the lowspin signal. Similar results were reported by Estabrook et al. [38], using ethanol. The ethylene glycolinduced $g \sim 2$ signal was qualitatively identical, within the noise limits of the experiment, as that observed in the unaltered sample, but the $g_{z}$ value of the 22-azacholesterol-induced signal was slightly greater than that of the ethylene glycol-induced spectrum. Changes of the other $g$-values were not appar- ent. The results of our EPR experiments are summarized in Table 2.

\section{DISCUSSION}

The cleavage of the side-chain of cholesterol is catalyzed by a cytochrome P-450-dependent enzyme system present in different endocrine tissues. The enzyme from hovine adrenal mitochondria was purified to homogeneity with a loss of contaminating $11 \beta$-hydroxylase activity and was characterized by Shikita and Hall $[22,39]$. Although great progress has been made in the isolation and characterization of the enzyme, knowledge still needs to be advanced to explain the mechanism of the oxidative cleavage of the $\mathrm{C}_{20}-\mathrm{C}_{22}$ carbon bond of cholesterol. According to the kinetic evaluations of Burstein and Gut [8], the pathways involving the sequential formation of a monohydroxy followed by the dihydroxycholesterol play only a minor role in the side-chain cleavage reaction. The observation by other workers [6.7] that (20S)-20-hydroxycholesterol and (20R,22R)-20,22-dihydroxycholesterol are better substrates than choles-

Table 2. Effect of ethylene glycol and 22-azacholesterol on EPR spectral measurements of adrenal mitochondrial P-450

\begin{tabular}{|c|c|c|c|c|c|c|c|c|c|c|c|}
\hline \multirow[b]{2}{*}{ Experiment } & \multicolumn{2}{|c|}{$\begin{array}{l}\text { Contents of } \\
\text { sample }\end{array}$} & \multicolumn{3}{|c|}{ Intensity/gain } & \multicolumn{3}{|c|}{$\begin{array}{l}\text { Apparent line } \\
\text { widths (gauss) }\end{array}$} & \multirow{2}{*}{$\begin{array}{c}\text { Intensity: } \\
\text { gain } \\
(\mathrm{g}-8)\end{array}$} & \multirow{2}{*}{$\begin{array}{c}\text { Width ito } \\
\text { low field) of } \\
y-8\end{array}$} & \multirow{2}{*}{$\begin{array}{c}\text { Intensity } \\
\text { gain } \\
\mid(j-6)\end{array}$} \\
\hline & $\mathrm{EG}^{*}(\mu \mathrm{1})$ & A $7 a-C^{*}(n M)$ & $y_{z}$ & $y_{y}$ & $g_{x}$ & $L_{z}$ & $L_{y}$ & $L_{x}$ & & & \\
\hline \multirow[t]{4}{*}{1} & 0 & 0 & 144 & 412 & 144 & 24.4 & 36 & 19.2 & 190 & 12.0 & \\
\hline & 20 & 0 & 154 & 392 & 148 & 30.0 & 28 & 24.4 & & & \\
\hline & 20 & 40 & 200 & 472 & 184 & 20 & 32 & 16 & & & \\
\hline & 40 & 80 & 220 & 500 & 208 & 20 & 32 & 15.2 & 129 & 11.0 & \\
\hline \multirow[t]{3}{*}{2} & 0 & 0 & 125 & 309 & 119 & 38 & 42 & 20 & 198 & 12 & 450 \\
\hline & 20 & 40 & & & & & & & 55 & 11.0 & 545 \\
\hline & 40 & 80 & 172 & 338 & 150 & 28 & 42 & 20 & 32 & 12.0 & 605 \\
\hline
\end{tabular}

* EG = ethylene glycol; aza-C $=22$-azacholesterol. 
terol and compete with it in the reaction should not be taken as proof of intermediacy, since 24-hydroxy-, 25-hydroxy- and 26-hydroxycholesterol all inhibited the reaction [21]. It is rather a measure of the ability of the system to catalyze a variety of reactions. Moreover, work from Lieberman's laboratory [14] has shown that a derivative of cholesterol having a t-butyl and a hydroxyl group at $\mathrm{C}-20$ positions and, therefore, incapable of forming a C-20,22-dihydroxy derivative could still give pregnenolone. The formation of $(20 \mathrm{R}, 22 \mathrm{R})$-20,22-dihydroxycholesterol whether resulting from a sequential hydroxylation or a rearrangement of the $20 x$-hydroperoxide as proposed by van Lier and Smith [25] does not, therefore, seem to be essential for the cleavage reaction. Recently, Burstein et al. [40] have incubated cholesterol with ${ }^{18} \mathrm{O}_{2}$ and ${ }^{16} \mathrm{O}_{2}$ and found that the ${ }^{16} \mathrm{O}_{2},{ }^{16} \mathrm{O},{ }^{18} \mathrm{O}$ and ${ }^{18} \mathrm{O}_{2}$ in the isolated 20,22 -dihydroxy-cholesterol exhibited a binomial distribution. This indicates that the oxygen atoms of the vicinal glycol are drawn at random from the available oxygen atom pool and, therefore, no significant insertion of an individual oxygen molecule occurs as would be obtained if the glycol arose from an intramolecular rearrangement of a hydroperoxide. Luttrell et al. [14] postulates the formation of short-lived radicals or ionic species complexing with the enzyme system. The traditional sidechain hydroxylated compounds would then be byproducts of the reaction, arising from the transient, enzyme-bound radicals or ionic species. This will explain their elusive nature in the free form.

In our enzymic inhibition studies, 22-azacholesterol curtailed, to relatively the same degree, the appearance in the incubation mixture of the free hydroxylated cholesterol derivatives. This observation does not answer the question of intermediacy of the hydroxylated steroids, but seems to indicate a role for 22-azacholesterol early in the sequence of events leading to the cleavage of the side-chain. Previously [15], we have reported the competitive nature of the inhibition of the CSCC reaction by 22-azacholesterol $\left(K_{i} 2.2 \mu \mathrm{M}\right)$. The competitive nature of the inhibition may indicate a common binding site or different binding sites with mutually exclusive binding properties.

Experiments outlined in this report indicate a competition in the spectral binding of cholesterol and 22-azacholesterol, although the former produces a type I whereas the latter, a "type II" spectrum. However, the results in this paper indicate that the binding of 22-azacholesterol is in reality a modified type II and is caused by the displacement of endogenous compounds (possibly cholesterol).

Several arguments are in favor of a close proximity between the substrate-binding site and the hemochrome site in various cytochrome P-450-dependent systems. Thus, several workers have found that metyropone competitively inhibits adrenal mitochondrial 11-hydroxylation of deoxycorticosterone (DOC) $[41,42]$; however, spectral studies have demonstrated that it coordinates to the heme of the cytochrome and not to the substrate site [36]. Recently, Griffin et al. [43], using a spin-labeled analog of metyropone, have provided support to their previous conclusion that the camphor and the metyropone binding sites of bacterial cytochrome P-450 overlap. Mailman et al. [44] have reported that nitro- gen-containing compounds in which the nitrogen is primarily an $\mathrm{sp}^{2}$ or $\mathrm{sp}^{3}$ hybrid and in which the nonbonded electron pair is accessible will cause typical type II spectra. Since in 22-azacholesterol the above requirements are fulfilled and in the light of the possible close proximity of the two binding sites, a starch for a type II spectrum hidden in the modified type II was begun. The absence of $\alpha$ - and $\beta$-bands of the reduced cylochrome between 500 and $600 \mathrm{~nm}$ and the inability to compete with carbon monoxide do not favor the hypothesis of a ligand formation between 22-azacholesterol and the heme of cytochrome $\mathrm{P}-450$. This is probably due to a relative inaccessibility of the lone pair of electrons on the nitrogen of 22-azacholesterol and/or the relative bulk of the molecule.

Estabrook et al. [38] have studied the interaction of drugs (ethylmorphine, hexobarbital and large concentrations of ethanol) with another P-450-dependent hydroxylase system, namely that catalyzing the 11-hydroxylation of DOC. Although these drugs are not metabolized by the adrenal system, they exhibited a type II spectra and facilitated the binding of the natural substrate DOC. Based on these observations, they hypothesized that the drugs displaced endogenously bound substrate but had no binding affinity of their own and were not metabolized.

In our system, 22-azacholesterol has a higher affinity than cholesterol to its binding site and apparently displaces it giving the observed optical and magnetic spectra. However, it did not facilitate the binding of cholesterol. This may be interpreted as: (a) the azasterol displaces cholesterol from its binding sites; however, it lacks the inherent ability to effect the structural changes in the enzyme that we observe as a high- to low-spin transition in the EPR spectra or a distinct type I spectrum; or (b) the azasterol displaces cholesterol (modified type II) and also provides a binding of its own (type I) and we are witnessing the algebraic summation of these two effects. The slight shift in $g_{z}$ observed in the low-spin EPR spectrum suggests that the azasterol exerts some specific influence on the ferric heme. The closeness of the structure of azasterol and cholesterol may favor this interpretation.

The isosteres of cholesterol having a nitrogen atom in different positions of the side-chain are close enough in structure to the parent compound and may prove to be useful tools in elucidation of the spatial arrangement of the binding and catalytic sites of cytochrome P-450.

Acknowledgement-The authors thank Mr. Ronald Langdon for his able technical assistance.

Note added in proof Evidence was recently presented that the conversion of cholesterol to pregnenolone proceeds via the sequence (22R)-22-hydroxycholesterol $\rightarrow$ (20R,22R)-20,22-dihydroxycholesterol [S. Burstein and M. Gut, Steroids 28, 115 (1976)].

\section{REFERENCES}

1. E. Staple, W. S. Lynn, Jr. and S. Gurin, J. biol. Chem, $219,845(1956)$

2. G. Constantopoulos, P. S. Satoh and T. T. Tchen, Biochem. biophys. Res. Commun. 8, 50 (1962). 
3. L. D. Wilson and B. W. Harding, Biochemistry 9, 1621 (1970).

4. K. D. Roberts, L. Bandy and S. Lieberman, Biochemistry 8, 1259 (1969).

5. S. Solomon, P. Levitan and S. Lieverman, Revue can. Biol. 15, $282(1956)$.

6. K. Shimizu. M. Hayano, M. Gut and R. I. Dorfman. J. biol. Chem. 236, 695 (1961).

7. K. Shimizu, M. Gut and R. I. Dorfman, J. biol. Chem. 237, 699 (1962)

8. S. Burstein and M. Gut. Steroids 14, 207 (1969).

9. S. Burstein. H. Zamoscianyk. H. L. Kimball, N. K. Chaudhuri and M. Gut, Steroids 15, 13 (1969).

10. S. Burstein, H. L. Kimball and M. Gut, Steroids 15, 809 (1969).

11. J. E. van Lier and L. L. Smith, Biochim. biophys. Acta 218, 320 (1970).

12. J. E. van Lier and L. L. Smith, Biochem. biophys. Res. Commu. 40. $510(1970)$.

13. J. E. van Lier, G. Kan and R. Langlois. Steroids 21 , $522(1973)$.

14. B. Luttrell. R. B. Hochberg. W. R. Dixon. P. D. McDonald and S, Lieberman, J. biol. Chem. 247, 1462 (1972).

15. R. E. Counsell, M. C. Lu, S. E1 Masty and P. A. Weinm hold. Biochent. Pharmac. 20, 2912 (1971).

16. O. H. Lowry. N. J. Rosebrough, A. L. Farr and R. J. Randall. $J$. biol. Chem. 193, 265 (1951).

17. T. Omura and R. Sato, J. blol. Chem. 239, 2370 (1964)

18. G. Palmer, in Methods in Enzymology (Eds. R. Estabrook and M. E. Pullman), Vol. 10, p. 594. Academic Press, New York (1967).

19. J. E. van Lier and L. L. Smith, Abstr. ORGN-58. One hundred fifty-sixth National Meeting. American Chemical Society. Atlantic City, N.J. Sept. 8-13, 1968.

20. J. E. van Lier, G. Kan. R. Langlois and L. L. Smith, in Biological Hydroxylation Mechanisms (Ed. G. S. Boyd), p. 21. Academic Press, London (1972).

21. E. R. Simpson and G. S. Boyd, Eur. J. Biochem. 2. 275 (1967).

22. M. Shikita and P. F. Hall, J, biol. Chem. 248, 5598 (1973).

23. S. Burstein. H. Zamoscianyk. N. Co, M. Adelson, D.
S. M. Prasad, A. Greenberg and M. Gut, Biochim. biophys. Acta 231, 223 (1971).

24. R. J. Kraaipoel, H. J. Degenhart, J. G. Leferenk, V. van Beek, H. Lecuw-Boon and H. K. A. Visser, J. Steroid Biochem. 5, 308 (1974).

25. J. E. van Lier and L. L. Smith, Biochim. himphys. Acta 210, 153 (1970).

26. S. Narasimhulu, Fedn Proc. 22. 530 (1963).

27. J. B. Schenkman, H. Remmer and R. W. Estabrook. Molec. Pharmac. 3, 113 (1967).

28. J. B. Schenkman and R. Sato, Molec. Phamac. 4, 613 (1968).

29. J. B. Schenkman, Hoppe-Seyler's 2. physiol. Chem. 349 , $1624(1968)$

30. G. S. Boyd, in Biological Hydroxylation Mechanisms (Ed. G. S. Boyd). p. 1. Academic Press. London (1972).

31. J. B. Schenkman. D. L. Centi, P. L. Moldeus and S. Orrenius. Drug Metah. Dispos. 1. 111 (1973).

32. F. Mitani and S. Horie, J. Biechem. Tokyo 65, 269 (1965)

33. S. Isaka and P. F. Hall, Biochem. hiophys. Res. Contmun. 43, 747 (1971).

34. S. C. Chen and B. W. Harding. J. biol. Chem. 249, 7263 (1973).

35. S. Burstein N. Co. M. Gut, H. Schleyer, D. Y. Cooper and $\mathrm{O}$. Rosenthal, Biochemistry 11, 573 (1972).

36. A. G. Hildebrandt, in Biological Hydroxylation Mechanisms (Ed. G. S. Boyd). p. 79. Academic Press. London (1972).

37. J. A. Whysner, J. Ramseyer and B. W. Harding. $J$. biol. Chem. 245, $5441(1970)$.

38. R. W. Estabrook, J. I. Mason, J. Baron. D. Lambeth and M. Waterman, Ann. N.Y. Acad. Sci. 212, 27 (1973).

39. M. Shikita and P. F. Hall. J. hiol. Chem. 248, 5605 (1973).

40. S. Burstein, B. S. Middleditch and M. Gut. Biochem. biophys. Res. Commun. 61, 692 (1974).

41. N. P. Sanzari and F. G. Peron. Steroids 8, 929 (1966).

42. R. J. Ertel and F. Ungar, Endocrinology 75, 949 (1964).

43. B. W. Griffin. S. M. Smith and J. A. Peterson, Archs Biochem. Biophys. 160, 323 (1974).

44. R. B. Mailman. A. P. Kulkami. R. C. Baker and E. Hodgson, Drug Metah. Dispos. 2. 301 (1974). 